\title{
Trends in notifiable blood lead levels in NSW, 1998-2008
}

\author{
Evan J. Freeman ${ }^{\mathrm{A}, \mathrm{B}, \mathrm{D}}$, Siranda Torvaldsen ${ }^{\mathrm{B}}$, \\ Adam Capon $^{\mathrm{C}}$ and Glenda L. Lawrence ${ }^{\mathrm{B}}$ \\ ${ }^{\mathrm{A}}$ NSW Public Health Officer Training Program, \\ NSW Ministry of Health \\ ${ }^{\mathrm{B}}$ School of Public Health and Community Medicine, \\ The University of New South Wales \\ ${ }^{\mathrm{C}}$ Environmental Health Branch, Health Protection NSW \\ ${ }^{\mathrm{D}}$ Corresponding author.Email: efree@doh.health.nsw.gov.au
}

\begin{abstract}
Aim: In the absence of published statewide notification data, the aim of this study was to analyse trends in notifiable blood lead levels (hereafter referred to as lead poisoning) in NSW from 1998 to 2008, to help inform lead poisoning notification policy. Methods: NSW blood lead poisoning notification data for 1998-2008 were extracted from the Notifiable Diseases Database and analysed by age, gender and Area Health Service of residence. Results: There were 6000 lead poisoning notifications from 1998 to 2008, with an average annual notification rate of 11.8 per 100000 population for 1998-2003. This rate declined to an average of 4.0 per 100000 population in the period 2004-2008. Males accounted for $92 \%$ of notifications, and males aged $20-59$ years had average notification rates between 20 and 27 per 100000 population. Children aged 0-4 years had notification rates of 9.3 per 100000 population in girls and 13.6 per 100000 population in boys. Conclusion: Notification rates have fallen dramatically, however children aged 0-4 years and men are disproportionately represented in lead poisoning notifications.
\end{abstract}

Lead is a naturally occurring mineral found within the Earth's crust in many parts of the world. ${ }^{1}$ Lead poisoning occuring after exposure to lead has been of public health importance worldwide for centuries. ${ }^{2}$ In 2009 the Australian National Health and Medical Research Council made a public statement that there is no safe level of lead exposure, and recommended that all Australians have blood lead levels less than $10 \mu \mathrm{g} / \mathrm{dL}^{3}$

The routes of lead exposure include ingestion, inhalation and skin contact. Once lead is absorbed into the bloodstream it spreads throughout the body, where it can affect the nervous, haematopoietic, endocrine, renal, skeletal and reproductive systems. ${ }^{1,4}$ The potential health outcomes from lead poisoning vary between individuals and are due to the route of exposure, the dose absorbed, the duration of exposure and the person's age. ${ }^{1,3,4}$ Children and pregnant women are considered the most sensitive to lead exposure; children absorb 40-70\% of ingested lead compared to $10-20 \%$ in adults, ${ }^{5}$ while women exposed before or during pregnancy transfer lead to the foetus via the placenta, and after pregnancy to the infant in breastmilk. $^{3}$

Acute lead poisoning occurs at blood lead levels of $70 \mu \mathrm{g} / \mathrm{dL}$ or higher, and is considered a clinical emergency. ${ }^{3}$ At these levels, signs and symptoms range from stomach pain and vomiting to encephalopathy and death. The long-term consequences of exposures in children include reduction in intellectual development even when blood lead levels are less than $10 \mu \mathrm{g} / \mathrm{dL}$. $^{6}$ Treatment for lead poisoning is limited to the use of chelating agents that bind to lead in the blood and assist excretion in urine. Chelating agents can be used in adults with levels above $50 \mu \mathrm{g} / \mathrm{dL}$, whereas chelation in children with levels less than $45 \mu \mathrm{g} / \mathrm{dL}$ does not improve long-term behavioural or cognitive outcomes. ${ }^{8}$ There is also concern that chelation therapy will redistribute lead to susceptible organs, including the brain, where it may be reabsorbed. ${ }^{9}$

Lead mining and smelter activities that cause lead-rich emissions to be blown into residential areas and deposited as dust in and around houses and gardens are the most common sources of contamination of human environments. ${ }^{1}$ In the past lead was used in applications including face powders, and for preserving wine, ${ }^{2}$ while more recently lead and lead alloys have been used in everyday products such as paint, car batteries and plastic coatings. ${ }^{3}$ In Australia, lead was added to petrol to improve engine combustion performance from the 1930s until 2002, despite public health concerns about lead exposure. ${ }^{10}$ The use of leaded petrol resulted in widespread contamination of dust and soil in urban and industrial areas, causing increased blood lead levels in people exposed, particularly children. ${ }^{11}$ Improved awareness about the 
effects of lead and the introduction of legislation in Australia has resulted in the reduction and removal of lead from car fuels and paints. ${ }^{12,13}$

In New South Wales (NSW) active screening for lead poisoning has been conducted for children and for workers exposed to lead since the early 1990s. In December 2011, the mandatory notification of blood lead concentrations $15 \mu \mathrm{g} / \mathrm{dL}$ or above was changed, under the NSW Public Health Act 1991*, to the lower level of $10 \mu \mathrm{g} / \mathrm{dL}$ or above. $^{14}$

The aim of this study was to describe trends in notifications of lead poisoning in NSW from 1998 to 2008 to help inform public health policy.

\section{Methods}

In NSW the notification of lead poisoning is mandatory for hospitals, clinicians and laboratories. Notifications are based on the results of a confirmatory venous blood sample to determine the lead concentration, which is measured in micrograms per decilitre $(\mu \mathrm{g} / \mathrm{dL})$. Between 1998 and 2008 , a blood lead concentration of $15 \mu \mathrm{g} / \mathrm{dL}$ or more was classified as lead poisoning and was notifiable to the then NSW Department of Health. ${ }^{15}$ Notified cases were then investigated by local public health units. ${ }^{16}$ The investigating public health unit staff entered demographic information and blood lead levels of the cases into the Notifiable Diseases Database (NDD), which was used for the collection of notifiable disease case information in NSW until the implementation of the Notifiable Conditions Information Management System in 2010. Data from active surveillance programs conducted in occupational settings and child blood lead screening programs were included in routine NDD data. Active surveillance programs included blood lead screening in children in the north Lake Macquarie area from 1993 to 2006, and continuous surveillance in children in Broken Hill since 1991.

All notifications of lead poisoning in NSW for the period 1998-2008 were extracted from the NDD using the Health Outcomes Information Statistical Toolkit (HOIST). The data were analysed using SAS $^{\circledR}$ (version 9.1.3, SAS Institute, Cary, NC, USA) and Microsoft Excel. Population estimates were obtained from the Australian Bureau of Statistics. Due to changes in Area Health Service boundaries, area of residence was defined by the NSW Health pre-2005 (former) Area Health Services $(n=17)$.

As a major source of lead notifications ceased operation in 2003, analysis by time period was divided into time period 1 (1998-2003) and time period 2 (2004-2008). Data were analysed by gender, age group, (former) Area Health Service, blood lead concentration and occupation. Occupational variables were identified from a predetermined

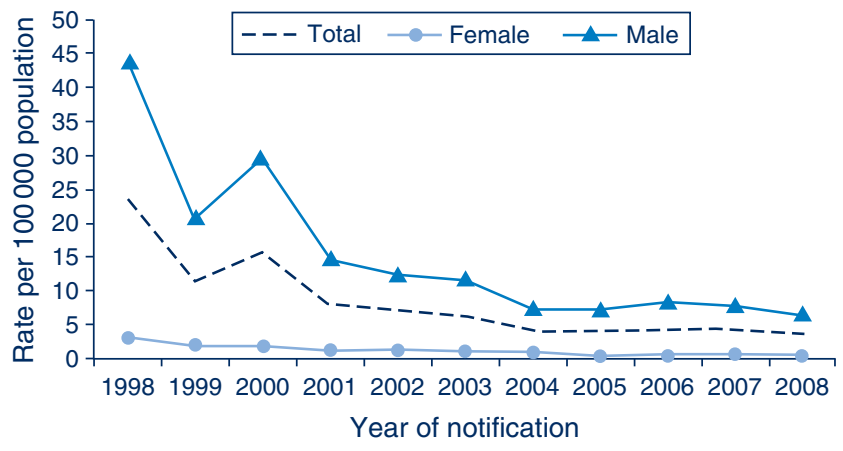

Figure 1. Annual lead poisoning notification rates per 100000 population, for males and females, NSW, 1998-2008.

Source: Notifiable Diseases Database (since 2010, the Notifiable Conditions Information Management System), NSW Ministry of Health.

list in the NDD; some of these served as a proxy for sources of lead exposure (e.g. lead smelter worker or miner).

Results

There were 6000 lead poisoning notifications in NSW for the period 1998-2008, with an average annual notification rate of 8.2 per 100000 population. The highest annual notification rate was in 1998 (23.0 per 100000 population, $n=1400)$. Notification rates declined each year, with the exception of 2000 (Figure 1).

\section{Gender and age}

Males accounted for $92 \%(n=5538)$ of all notifications with a notification rate of 15.2 per 100000 population for the period 1998-2008. The highest notification rate for males was 43.0 per 100000 population in 1998; by 2004, annual notification rates in males had decreased to below 10.0 per 100000 population (Figure 1). For females, the notification rate began at below 5.0 per 100000 population in 1998 and steadily declined to below 1.0 per 100000 population in 2008 (Figure 1).

People notified with lead poisoning between 1998 and 2008 ranged in age from 0 to 87 years. Men aged 25-34 had the highest notification rate of 27.1 per 100000 population, while the lowest notification rates were in 10-14-year old boys and girls. The gender differences become more noticeable at 15 years of age (Figure 2). Seventy-eight percent of notifications $(n=4701)$ were observed in men aged 20-59 years, who had an annual notification rate of almost 70.0 per 100000 population in 1998 , which declined to 10.0 per 100000 population in 2004 .

The 0-4-year age group accounted for 9.3\% of notifications ( $n=559$ ), of which $60 \%$ were in boys. The notification rate in girls aged $0-4$ years was 9.3 per 100000 population, and for the same age group of boys, 13.6 per 100000 population (Figure 2). The highest annual 


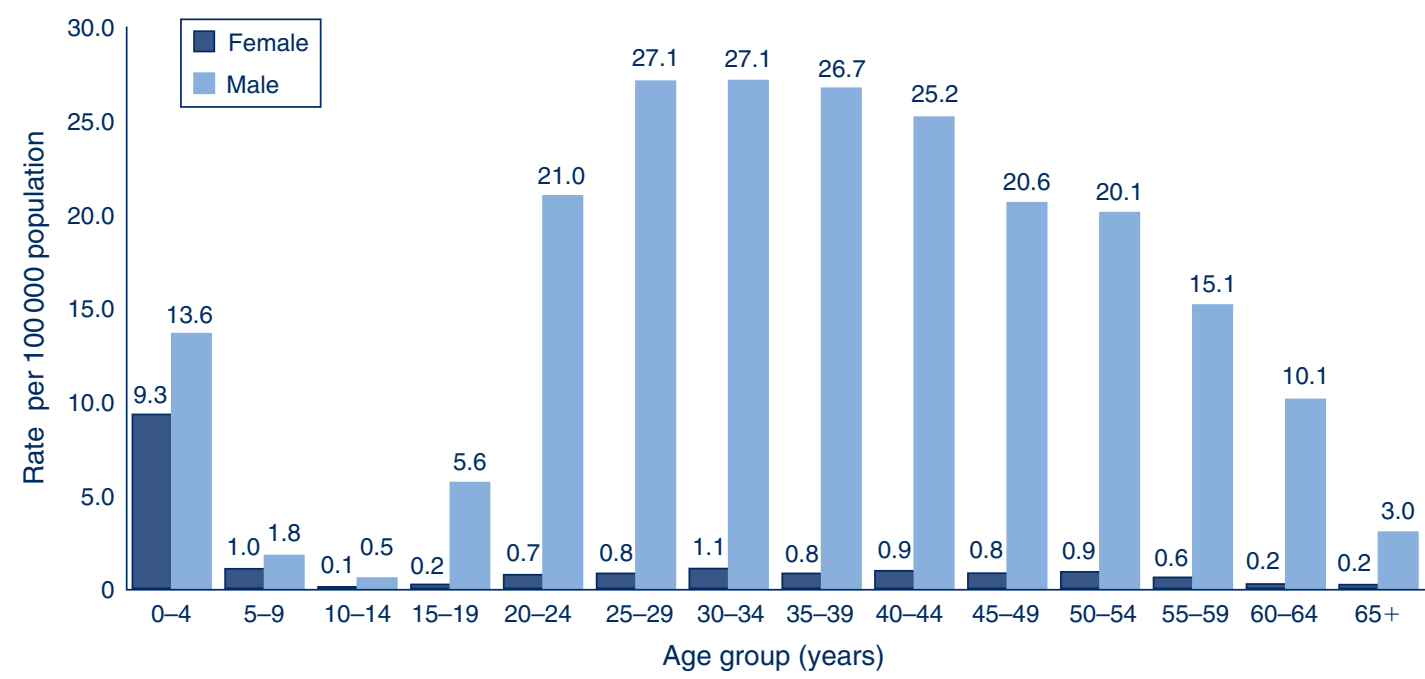

Figure 2. Average annual lead poisoning notification rates per 100000 population, for males and females and by age group, NSW, 1998-2008.

Source: Notifiable Diseases Database (since 2010, the Notifiable Conditions Information Management System), NSW Ministry of Health.

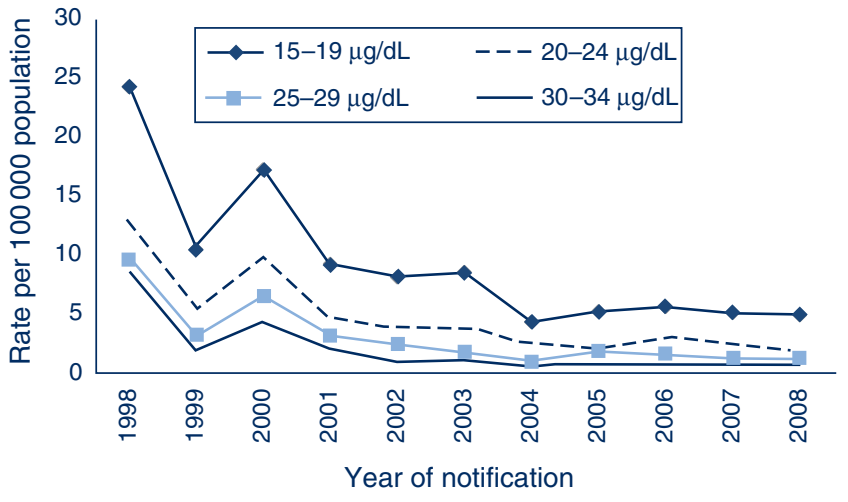

Figure 3. Annual lead poisoning notification rates per 100000 population for four blood lead concentrations, in men aged 20-59 years, NSW, 1998-2008.

Source: Notifiable Diseases Database (since 2010, the Notifiable Conditions Information Management System), NSW Ministry of Health.

notification rate for boys aged $0-4$ years was 30.0 per 100000 population in 1999.

\section{Blood lead concentrations}

Blood lead concentrations were recorded for $96.6 \%$ $(n=5795)$ of notifications. Forty-three percent $(n=2503)$ of blood lead concentrations were in the lowest notifiable range $(15-19 \mu \mathrm{g} / \mathrm{dL})$, while $54 \%$ $(n=3011)$ were in the $20-49 \mu \mathrm{g} / \mathrm{dL}$ range, $2 \%(n=125)$ were in the $50-69 \mu \mathrm{g} / \mathrm{dL}$ range, and $1 \%(n=56)$ were $70 \mu \mathrm{g} / \mathrm{dL}$ or above. Figure 3 shows a further breakdown of notification rates by year, stratified by blood lead concentrations, in men aged 20-59 years, and demonstrates the downward trend in notification rates of blood lead concentrations in all years except 2000 .

\section{Geographic distribution of notifications}

Sixty-two percent ( $n=3732)$ of lead poisoning notifications were in locations outside of Sydney. The highest notification rates in 1998-2003 were 227.4 per 100000 population in the former Far West Area Health Service, and 52.1 per 100000 population in the former Hunter Area Health Service (Table 1). Over the period of analysis, lead poisoning notifications declined by $50 \%$ or greater in most Area Health Services: the former Macquarie Area Health Service increased by $230 \%$, and the former Mid West Area Health Service increased by 39\% (Table 1). From 1998 to 2008, 68.9\% of lead poisoning notifications in children aged $0-4$ years were in the former Far West Area Health Service which had a notification rate of 104.5 per 10000 population. The former Hunter Area Health Service accounted for 14\% (1.9 per 10000 population), while $12.3 \%$ of notifications in the 0-4-year age group were from Sydney $(0.24$ per 10000 population).

\section{Occupation}

Occupational information was recorded for $37 \%$ of all adult notifications. Women had occupation recorded in $10 \%(n=29)$ of cases, while $40 \%$ of men had occupation recorded. Occupations with the highest proportions of notifications were lead smelter employees (37\%; $n=735)$ and miners $(23 \% ; n=453)$. For the period 1998-2002 (with the exception of 1999), smelter workers had the highest frequency of notifications, after which (with the exception of 2005) miners had the highest number of notifications (Figure 4). Other occupational categories identified with high notification rates included contractors (13\%) and factory workers $(10 \%)$. 
Table 1. Average annual lead poisoning notifications and rates per 100000 population, in NSW, by former Area Health Service (AHS), categorised by two time periods (TP1: 1998-2003 and TP2: 2004-2008) and the percentage reduction in notifications between time periods

\begin{tabular}{|c|c|c|c|c|c|c|c|c|}
\hline \multirow[b]{2}{*}{$\begin{array}{l}\text { Area Health Service } \\
\text { of residence }\end{array}$} & \multicolumn{3}{|c|}{ 1998-2003 } & \multicolumn{3}{|c|}{ 2004-2008 } & \multirow[b]{2}{*}{ Total } & \multirow[b]{2}{*}{$\begin{array}{l}\% \text { change } \\
\text { TP 1-TP } 2\end{array}$} \\
\hline & $n$ & Rate & $\%$ Male & $n$ & Rate & $\%$ Male & & \\
\hline Central Coast & 70 & 4.0 & 87 & 26 & 1.7 & 100 & 96 & -63 \\
\hline Central Sydney & 240 & 8.2 & 84 & 70 & 2.7 & 90 & 310 & -71 \\
\hline Far West & 664 & 227.4 & 76 & 80 & 35.4 & 63 & 744 & -89 \\
\hline Greater Murray & 42 & 2.7 & 95 & 27 & 2.0 & 89 & 69 & -36 \\
\hline Hunter & 1713 & 52.1 & 96 & 224 & 7.7 & 94 & 1937 & -87 \\
\hline Illawarra & 197 & 9.3 & 98 & 58 & 3.1 & 97 & 255 & -71 \\
\hline Macquarie & 72 & 11.5 & 99 & 240 & 46.4 & 96 & 312 & +230 \\
\hline Mid North Coast & 35 & 2.2 & 91 & 9 & 0.6 & 78 & 44 & -74 \\
\hline Mid West & 33 & 3.2 & 94 & 46 & 5.3 & 87 & 79 & +39 \\
\hline New England & 45 & 4.2 & 96 & 13 & 1.5 & 100 & 58 & -71 \\
\hline Northern Rivers & 57 & 3.6 & 86 & 30 & 2.1 & 77 & 87 & -47 \\
\hline Northern Sydney & 129 & 2.8 & 92 & 48 & 1.2 & 98 & 177 & -63 \\
\hline South Eastern Sydney & 153 & 3.3 & 90 & 79 & 2.0 & 97 & 232 & -48 \\
\hline South Western Sydney & 578 & 12.3 & 97 & 172 & 4.2 & 99 & 750 & -70 \\
\hline Southern & 27 & 2.4 & 93 & 22 & 2.1 & 95 & 49 & -19 \\
\hline Wentworth & 126 & 6.7 & 94 & 62 & 3.9 & 94 & 188 & -51 \\
\hline Western Sydney & 432 & 10.3 & 96 & 144 & 3.8 & 94 & 576 & -67 \\
\hline Overseas & 1 & - & 100 & 1 & - & 100 & 2 & - \\
\hline Not stated & 12 & - & 83 & 23 & - & 96 & 35 & - \\
\hline Total & 4626 & 11.8 & 92 & 1374 & 4 & 93 & 6000 & -70 \\
\hline
\end{tabular}

Analysis was divided into TP1: 1998-2003 and TP2: 2004-2008 because in 2003 a major source of lead notifications ceased operation. Source: Notifiable Diseases Database (since 2010, the Notifiable Conditions Information Management System), NSW Ministry of Health.

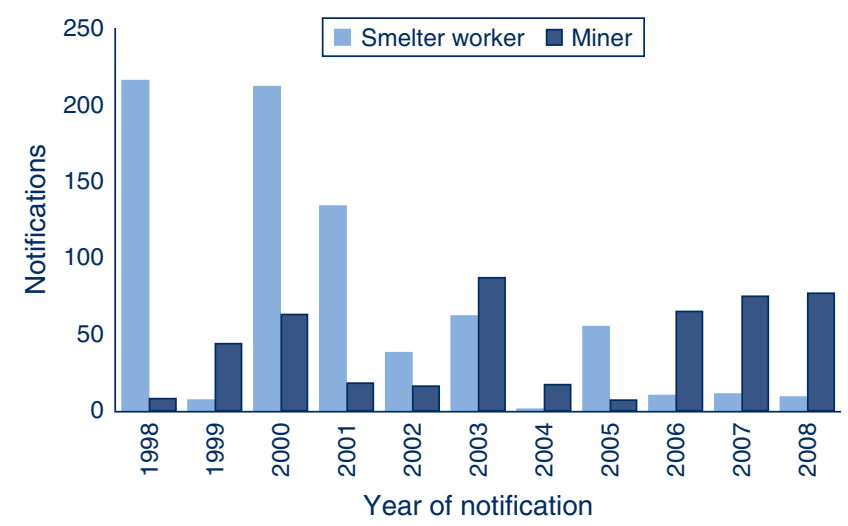

Figure 4. Annual notifications of lead poisoning in lead smelter workers and miners, NSW, 1998-2008.

Source: Notifiable Diseases Database (since 2010, the Notifiable Conditions Information Management System), NSW Ministry of Health.

\section{Discussion}

There was a 70\% reduction in lead poisoning notifications in NSW from 1998 to 2008, with fewer than 250 notifications each year since 2004. Men of working age and children aged $0-4$ years are disproportionately represented in lead poisoning notifications, with rates among men more than three times higher than among women. Populations in the former Far West, Hunter and Macquarie Area Health Services of NSW had the highest notification rates for lead poisoning.

The interpretation of this study is limited by data quality, with more than half of adult cases missing occupational data. Because the source of lead exposure was not available, occupation was used as a proxy for the source of exposure. In future, a review of case files from lead poisoning investigations and the recent inclusion of a variable for exposure site in the new notification data management system will help describe sources, without the need to use proxies. There is also likely to be a selection bias due to active surveillance programs, and greater awareness of public health practitioners in geographical areas, age groups and occupations at high risk. Screening has been important for understanding the epidemiology of lead exposure, because the acute symptoms of lead poisoning are not present at lower blood lead concentrations. ${ }^{1,3}$ However, the likely selection bias for children and men means that women will tend to be under-represented in notification data. The reporting of more robust 
information about testing, including the reason for testing (i.e. occupational vs. childhood screening or clinical suspicion) would help clarify the extent of this selection bias.

Notification rates of lead poisoning in NSW have been linked to occupational activities. For more than 100 years, mining and, formerly, smelting, have occurred in Broken Hill (former Far West Area Health Service), ${ }^{17}$ and smelting has occurred in the north Lake Macquarie area (former Hunter Area Health Service). ${ }^{18}$ There are marked differences in the ages of notified cases in these two locations. In the former Hunter Area Health Service, $90 \%$ of cases were in adults aged 20-59 years, whilst in the former Far West Area Health Service, children aged 0-4 years accounted for $52 \%(n=385)$ of notified cases. In comparison, the former Hunter Area Health Service had 4\% $(n=78)$ of notifications in the $0-4$-year age group. An explanation for this difference is the location of Broken Hill city, which is in the immediate vicinity of the active mine site with above ground historical waste disposal, and regional soils that have natural lead deposits. These sources produce ongoing exposure from lead-laden dust in and around houses where children play. ${ }^{19}$

Occupational exposures are also likely to account for the differences in notification rates between men and women which became more evident from the age of 15 years. In the former Hunter Area Health Service, lead poisoning notifications reduced following the closure of the Lake Macquarie smelter in $2003 .{ }^{20}$ Increased lead mining activity in the former Macquarie Area Health Service (Cobar) since $2003^{21}$ has resulted in miners being the most frequently notified occupation. Other occupations and hobbies that have been associated with lead exposures include battery making and recycling, soldering, stained glass manufacture and lead-based paint abatement. ${ }^{3,22}$

Since 1991 the blood lead screening of children in Broken Hill has underpinned education and risk reduction interventions provided to individuals and their families. ${ }^{23,24}$ These interventions resulted in almost $75 \%$ of children aged $1-4$ years recording blood lead levels below $10 \mu \mathrm{g} / \mathrm{dL}$ by $2007 .{ }^{25}$ In the north Lake Macquarie area, the positive influence of public health action allowed active surveillance to stop after mean blood lead levels in children decreased to less than $5 \mu \mathrm{g} / \mathrm{dL}$ in $2006,{ }^{18} 3$ years after the closure of the smelter.

From December 2011, the notifiable blood lead level in NSW has been reduced to $10 \mu \mathrm{g} / \mathrm{dL}$ in line with the current National Health and Medical Research Council recommendation. ${ }^{3}$ A review conducted by the Centers for Disease Control and Prevention in the United States concluded that there is sufficient evidence for adverse health effects in children and adults at blood lead concentrations below $5 \mu \mathrm{g} / \mathrm{dL}^{26}$ Both of these recommendations have implications for public health policy and practice in NSW.

\section{Conclusion}

Active surveillance practices for lead poisoning in NSW have enhanced our knowledge of this condition, particularly in the former Hunter and Far West Area Health Services. Encouragingly, a large reduction in notifications and the concentrations of blood lead samples was observed from 1998 to 2008. Despite these reductions, there remains an over-representation of children and miners in more recent years of analysis. Importantly, these findings support ongoing primary prevention, improved surveillance measures and the mandatory notification of lead poisoning, which remain essential to addressing lead poisoning in NSW.

\section{Acknowledgment}

This work was completed while Evan Freeman was an employee of the NSW Public Health Officer Training Program, funded by the NSW Ministry of Health. He undertook this work while based at the Environmental Health Branch, Health Protection NSW.

\section{References}

1. Agency for Toxic Substances and Disease Registry (ATSDR). Toxicological Profile for Lead. U.S. Department of Health and Human Services: Agency for Toxic Substances and Disease Registry. October 2007. Available at: http://www.atsdr.cdc.gov/ ToxProfiles/tp13.pdf (Cited 4 February 2013).

2. Lewis J, editor. Lead poisoning: a historical perspective. United States Environment Protection Agency; 1985. Available at: http://www.epa.gov/aboutepa/history/topics/perspect/lead.html (Cited 4 February 2013).

3. National Health and Medical Research Council. Information Paper. Blood lead levels for Australians. August 2009. Available at: http://www.nhmrc.gov.au/_files_nhmrc/publications/ attachments/gp2-lead-info-paper.pdf (Cited 4 February 2013).

4. Health Protection Agency (HPA). Lead. Toxicological Overview. United Kingdom 2007. Available at: http://www.hpa.org. uk/webc/HPAwebFile/HPAweb_C/1194947332124 (Cited 5 February 2013).

5. Gracia RC, Snodgrass W. Lead toxicity and chelation therapy. Am J Health Syst Pharm 2007; 64(1): 45-53. doi:10.2146/ ajhp060175

6. Needleman HL, Gunnoe C, Leviton A. Deficits in psychologic and classroom performance of children with elevated dentine lead levels. $N$ Engl J Med 1979; 300: 689-95. doi:10.1056/ NEJM197903293001301

7. Association of Occupational and Environmental Clinics (AOEC). Medical management guidelines for lead-exposed adults. Revised 24 April 2007. Available at: www.aoec. org/documents/positions/MMG_FINAL.pdf (Cited 2 February 2013).

8. Dietrich KN, Ware JH, Salganik M, Radcliffe J, Rogan WJ, Rhoads GG et al. Effect of chelation therapy on the neuropsychological and behavioral development of lead-exposed children after school entry. Pediatrics 2004; 114(1): 19-26. doi:10.1542/peds.114.1.19 
9. Goyer RA, Cherian MG, Jones MM, Reigart JR. Role of chelating agents for prevention, intervention, and treatment of exposures to toxic metals. Environ Health Perspect 1995; 103(11): 1048-52. doi:10.1289/ehp.951031048

10. Markowitz G, Rosner D. "Cater to the children": the role of the lead industry in a public health tragedy, 1900-1955. Am J Public Health 2000; 90(1): 36-46. doi:10.2105/AJPH.90.1.36

11. Gulson B, Mizon K, Taylor A, Korsch M, Stauber J, Davis JM et al. Changes in manganese and lead in the environment and young children associated with the introduction of methylcyclopentadienyl manganese tricarbonyl in gasoline preliminary results. Environ Res 2006; 100(1): 100-14. doi:10.1016/j.envres.2005.03.013

12. Australian Government. National phase out of leaded petrol. Available at: http://www.environment.gov.au/atmosphere/ airquality/publications/qa.html (Cited 2 February 2013).

13. Taylor MP, Schniering CA, Lanphear BP, Jones AL. Lessons learned on lead poisoning in children: one-hundred years on from Turner's declaration. J Paediatr Child Health 2011; 47(12): 849-56. doi:10.1111/j.1440-1754.2010.01777.x

14. NSW Government. Public Health Amendment (Notifiable Lead Level) Regulation 2011 under the Public Health Act 1991. Available at: http://www.legislation.nsw.gov.au/sessionalview/ sessional/sr/2011-672.pdf (Cited 4 February 2013).

15. Communicable Diseases Branch. Lead poisoning. Notifiable Diseases Manual. Sydney: NSW Department of Health; 2002.

16. Birdsey R. The Lead Reference Centre. NS W Public Health Bull 1997; 8(11-12): 89-90. doi:10.1071/NB97034

17. NSW Department of Environment and Heritage. Broken Hill Complex - regional history. Available at: http://www.environment. nsw.gov.au/bioregions/BrokenHillComplex-RegionalHistory. htm (Cited 4 February 2013).

18. Hunter New England Area Health Service. Environmental Health Centre Annual Report 2005-2006. Sydney: NSW Health; 2006.
19. Boreland F, Lesjak M, Lyle D. Evaluation of home lead remediation in an Australian mining community. Sci Total Environ 2009; 408(2): 202-8. doi:10.1016/ j.scitotenv.2009.10.013

20. Hunter New England Population Health. Community Information Paper. North Lake Macquarie Blood Lead Monitoring Service. Summary of Results (July 2005-June 2006). Available at: http://www.hnehealth.nsw.gov.au/_data/assets/pdf_file/ 0012/62022/EHCBloodLeadTesting2006.pdf (Cited 4 February 2013).

21. CBH Resources Limited. Company profile 2010. Available at: http://www.cbhresources.com.au/operations/endeavor-mine. htm (Cited 1 November 2011).

22. Landrigan PJ, Todd AC. Lead poisoning. West J Med 1994; 161(2): 153-9.

23. Kardamanidis K, Lyle D, Boreland F. Addressing decreasing blood lead screening rates in young children in Broken Hill, NSW. N S W Public Health Bull 2008; 19(9-10): 180-2. doi:10.1071/NB08040

24. Boreland F, Lesjak M, Lyle D. Managing environmental lead in Broken Hill: a public health success. N S W Public Health Bull 2008; 19(9-10): 174-9. doi:10.1071/NB07099

25. Population Health Division. The health of the people of New South Wales - Report of the Chief Health Officer, 2008. Sydney: NSW Department of Health; 2008.

26. Centers for Disease Control and Prevention. Low lead level exposure harms children: a renewed call for primary prevention - Report of the Advisory Committee on Childhood Lead Poisoning Prevention. 4 January 2012. Available at: http:// www.cdc.gov/nceh/lead/ACCLPP/Final_Document_011212. pdf (Cited 4 February 2013).

*The Public Health Act 2010 (NSW) (http://www.health.nsw.gov.au/phact/)

The Public Health Act 2010 (NSW) was passed by the NSW Parliament in December 2010 and commenced on 1 September 2012. The Public Health Regulation 2012 was approved in July 2012 and commenced, along with the Public Health Act 2010 (NSW), on 1 September 2012. The objectives of the Regulation are to support the smooth operation of the Act. The Act carries over many of the provisions of the Public Health Act 1991 (NSW) while also including a range of new provisions. 